\title{
Cordline multi-motor electric drive with energy recovery
}

\author{
Rishat Ganiev ${ }^{1, *}$ \\ ${ }^{1}$ Kazan National Research Technological University, Institute of chemical technology, 423570 Avenue of Builders, 47, Nizhnekamsk, \\ Republic of Tatarstan, Russian Federation
}

\begin{abstract}
The article offers a variant of developing a cordline electric drive in the production of automobile tires to increase the energy-efficient due operation of production lines based on interconnected electric drives with energy recovery. The modes of operation of the technological line of cord production with energy recovery is possible in the network are shown, requirements for the drive system are drawn up. Simulations in Matlab 10, Simulink and SimPowerSystems carried out the research. The developed version of the frequency-controlled electric drive allows increasing the energy efficiency of production lines in the production technology of automobile tires by using generator modes of asynchronous motors as a part of frequency-controlled electric drives.
\end{abstract}

\section{Introduction}

Production of cord consists of impregnation of synthetic fabric with latex followed by rubberization of the fabric on multi-roll calender rolls. Calender rolls consist of mechanisms driven by reversible multi-quadrant electric drives with varying signs of speed and torque [8]. Before cutting, a roll of fabric is loaded into the cutting line at a speed of $3 \mathrm{~m} / \mathrm{min}$ with a tension of about $50 \mathrm{kgf}$ using a rolling device and a pulling station. After loading the fabric and beginning to rubberize, the speed of movement of the fabric increases to $45-50 \mathrm{~m} / \mathrm{min}$. Hence, the speed control range of the drive must be at least (1:15).

Braking modes when the line is stopped are accompanied by generator modes in the electric drive of the seaming device. The braking energy released when the line is stopped for loading can be used to power the drives of the pulling device. To research on the possibility of recovery, let's consider the general requirements for a multi-motor drive of a cord line.

\section{Requirements to drive}

Since the volume of the supplied rubber mixture changes during the calendering process, which causes a change in the load moment, it is necessary to provide control of the drive moment. According to the technology on the line for impregnating cord fabric, the electric drive must provide a number of additional requirements:

- speed matching of individual line mechanisms;

- setting and stabilization of tension on various sections of the cord line, as well as ensuring stable operation of the multi-motor electric drive;
- maintain a steady speed in steady mode (with an accuracy of $\pm 5 \%$ when changing the static torque from 0.25 to 1.00 of the rated motor torque);

- compensation of static and dynamic moments;

- maintaining the degree of filling of the compensator and the continuity of the technological process when replacing rolls in the electric drives of rolling and rolling devices.

- reversing and limiting the time of emergency braking of the rolls (no more than $1 / 4$ of the circumference of the roll). Precision maintain set parameters of the electric drive should provide a steady-state deviation of maximum operating speed of the line in the static operation - no more than $\pm 1 \%$ of nominal operating speed at a static voltage mains three-phase $\mathrm{AC}+10 \%$, $15 \%$, frequency $\pm 1 \%$, the ambient temperature \pm 10 degrees C [1].

\section{The existing scheme of drives}

At now each cordline motor is powered individually from frequency converters. For this purpose, a single three-winding power transformer is used, the output voltage of the secondary winding of which is connected to the input of frequency converters. Figure 1 shows the General connection diagram for frequency converters. The scheme also includes: for further research, two electric drives of the "KAMA-3 "equipment based on the "Repique" line are selected: M20, which is an electric drive of the tension roller , and M70, which is an electric drive of the rolling device, one of which is powered by a frequency Converter Mitsubishi FR-A741-22k, and the second is powered by a frequency Converter Mitsubishi FR-A740-00620 EC.

For researching the operating modes of the cordline electric drives, an increase in the voltage in the DC link 


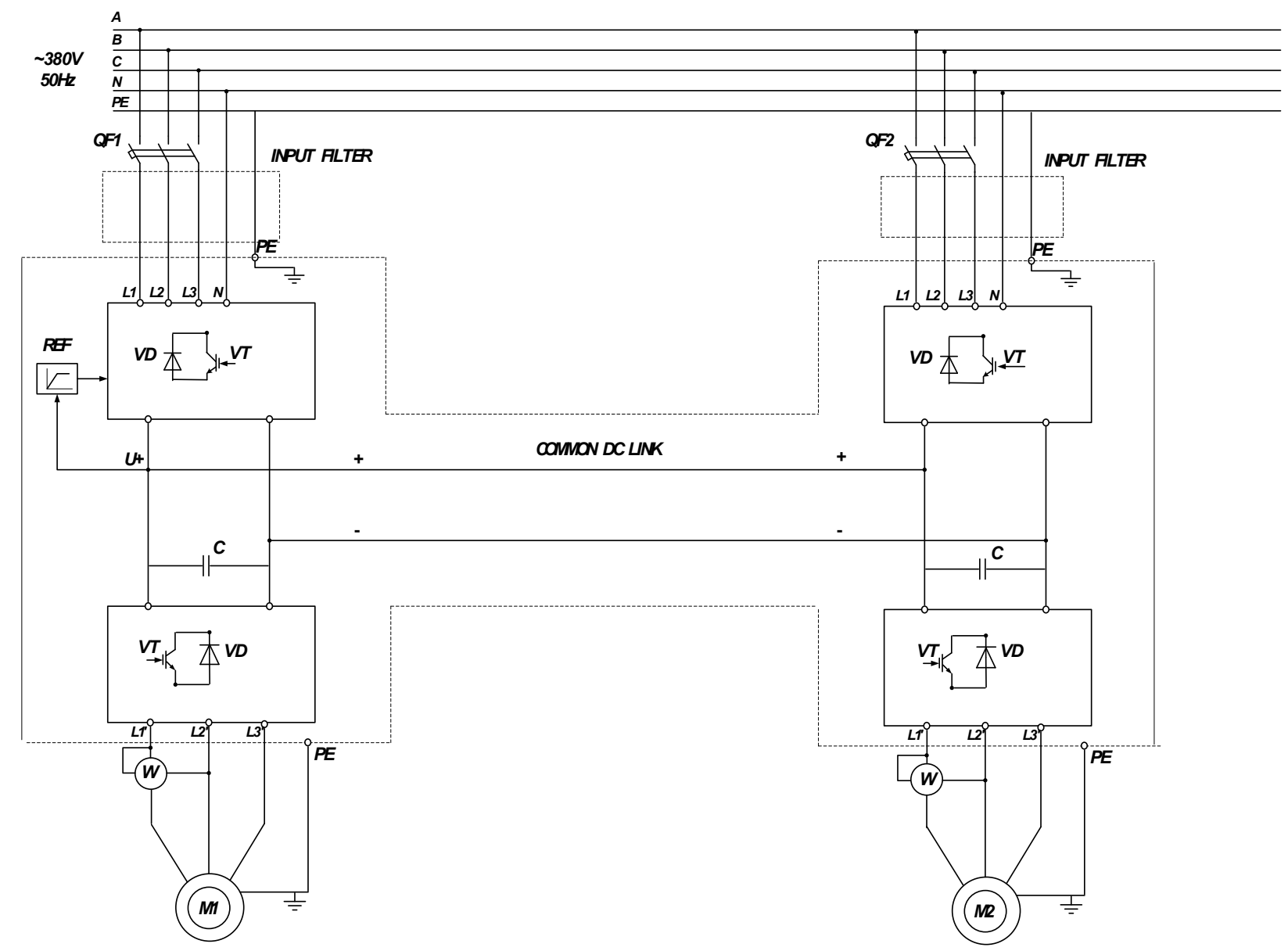

Fig. 1. Experimental scheme for research.

of the tension roller electric drive at the time of acceleration of the process line was registered. It is determined that the line speed is ahead of the specified rotor speed of the tensioner motor, and the rotor speed begins to exceed the speed of rotation of the stator electromagnetic field, and the motor goes into generator mode.

A Mitsubishi FR-A741 frequency Converter with recovery capability is used to power the electric motor . The recovered energy of the tension roller electric drive can be used to power another electric drive of position M70. Combining converters with a common DC bus will solve the problem of using energy recovery.

Frequency Converter FR-A741 for low and medium power ranges is an inverter with a built-in function of returning (recovering) stored energy from the engine to the network. The idea to combine a conventional inverter

(for example, a series of frequency converters Mitsubishi FR-A740) with a power return device will eliminate the brake resistors and significantly reduce the time of stopping the drive, as well as increase the efficiency of the line as a whole.

\section{Experimental scheme for research}

Two frequency converters with the possibility of energy recovery were adopted for the study. The connection diagram with a common DC link of these converters is shown in figure 1.

The scheme works as follows: at the moment when M1 (M2) is in braking mode, and M2 (M1) is in acceleration mode, the energy stored in M1 (M2) will flow to M2 (M1), respectively, the energy from the network will be consumed in a smaller amount, which can be observed with the help of wattmeters installed at the output of the if. In the case when both engines are running in braking modes, the energy will be recovered to the network. The intensity setter (ZI) serves as a regulator for switching the rectifier to the inverter mode when the voltage on the bus bridge of the DC link increases in the case of simultaneous operation of both electric motors in generator mode

\section{Computer Simulation of recovery modes}

In the Matlab Simulink program, a model of an electric drive was assembled to study the generator mode according to the scheme "Network - secondary power source (SPS) - power semiconductor Converter electric machine". The model is shown in figure 2. [2]. In this scheme, the motor and its Converter are represented by a DC link, respectively, a passive activeinductive circuit RL and a regulated voltage source (EMF). This substitution scheme is valid for both a DC 


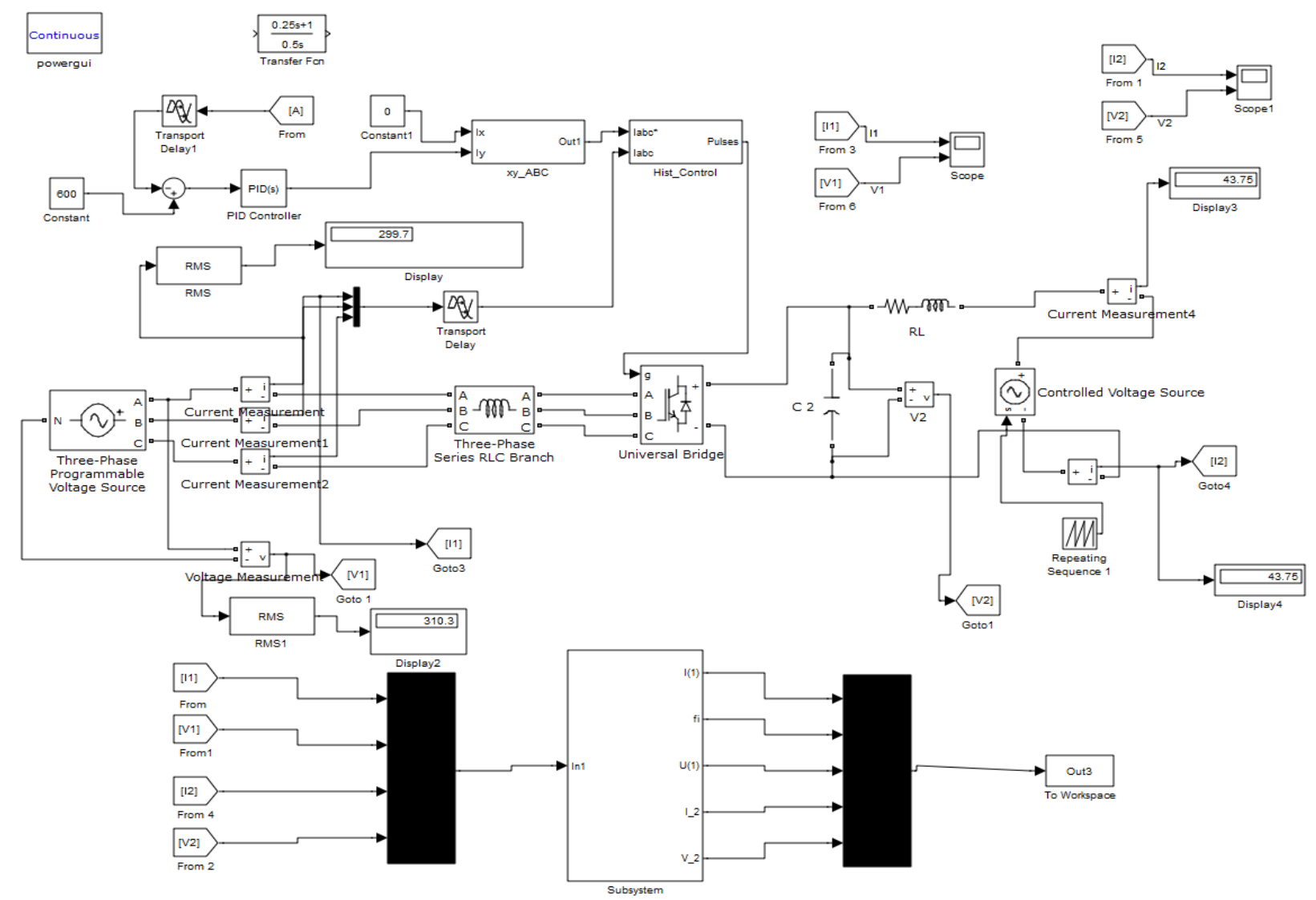

Fig. 2. Model of a secondary power source with energy recovery in the network.

motor with a pulse-width Converter and an asynchronous motor with a self-contained voltage inverter. The filter capacitor is always connected to the secondary power supply terminals. The coupling equation for the load current has the form:

$$
L\left(\frac{d i_{H}}{d t}\right)+R i_{H}=U_{d}-E(t)
$$

If the motor is motoring mode of operation and motor connected to the output of the Converter, the voltage Ud on the capacitive element is greater than the EMF value of the machine, the current sign is positive, the energy flow is directed from the power source to the motor. In the case of generator mode of the motor, the EMF exceeds the value of the capacitor voltage, the load current is negative, and the energy flow is directed from the motor to the power source.

To implement the secondary power supply model in the current control loop, the Simulink function package is used, as well as a package with a set of special functions of SimPowerSystems. To configure the main block variables in the specified packages, there is a parameters window. Each the Simulink and SimPowerSystems package block has configuration window for basic parameters. In the block $x, y-A B C$, the coordinate system $(\mathrm{x}, \mathrm{y})$ is converted from rotating to stationary A, B, C according to the following equations:

$$
\begin{gathered}
u_{\alpha}=u_{x} \cos \left(\omega_{1} t\right)-u_{y} \sin \left(\omega_{1} t\right) \\
u_{\beta}=u_{y} \cos \left(\omega_{1} t\right)+u_{x} \sin \left(\omega_{1} t\right) \\
u_{A}=u_{\alpha} \\
u_{B}=-0,5 u_{\alpha}-\sqrt{ } 0,865 u_{\beta} \\
u_{C}=-0,5 u_{\alpha}+\sqrt{ } 0,865 u_{\beta}
\end{gathered}
$$

In this computer simulation, the load current is changed due to the change of the electromotive force of the machine. The $\mathrm{xy}_{-} \mathrm{ABC}$ subsystem converts the $\mathrm{XY}$ coordinates (coordinates of DC signals) into a threephase $\mathrm{ABC}$ current system, where they are set for motor control. The Hist Control subsystem includes relay controllers. The Subsystem model is a measurement model. In this scheme, input and output connectors and two harmonic analysis blocks from the SimPowerSystems Extras Measurement library are connected. [1].

\section{The results of computer simulation}

Figure 3 shows quasi-steady processes in the system at the moment when the current at the output of the secondary power supply is measured according to the 
trapezoidal law. At a time interval where the load current is constant, the system operates in a steady state (motor at a positive current, generator - at a negative). During the time interval, where the current changes according to the linear law, a transient mode of operation of the system will be observed.
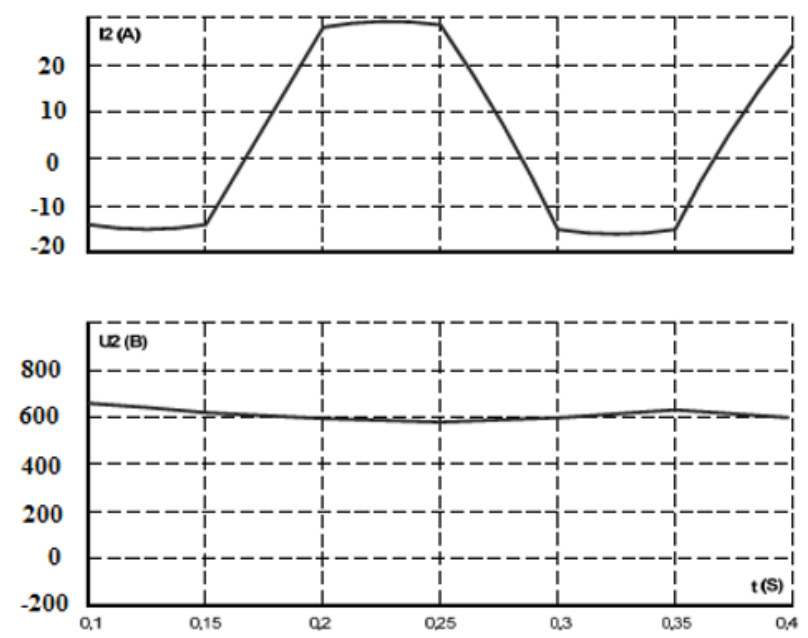

Fig. 3. Electromagnetic processes in SPS with electric drive energy recovery in the network.

Figure 4 shows the electromagnetic processes in the steady-state operation mode. To obtain the characteristics of electromagnetic processes in the entire range of changes in the load current of the secondary power supply, a signal is formed that changes according to a linear law in the Repeating Sequence block. The current takes a negative sign in the generator mode and a positive sign in the motor mode.
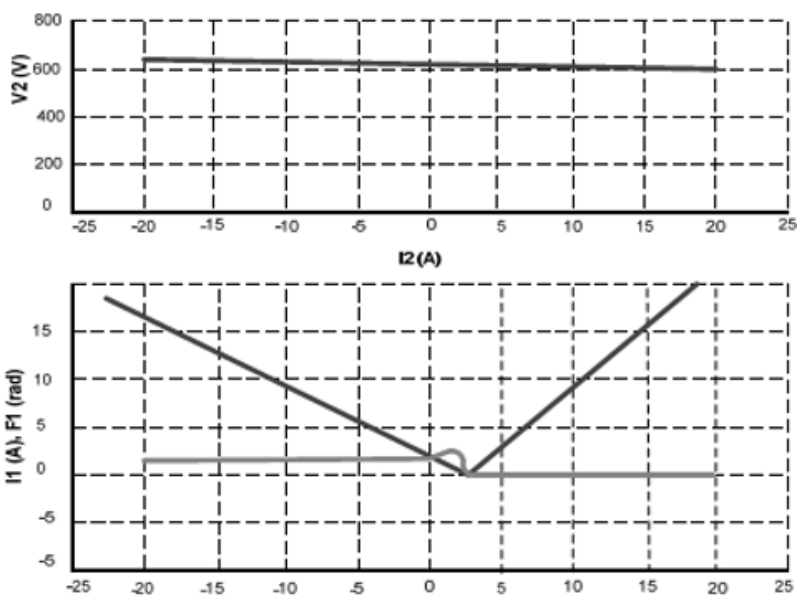

Fig. 4. Electromagnetic characteristics of SPS with electric drive energy recovery in the network.

This experiment was carried out on a laboratoryindustrial complex with all possible losses for two electric drives with a frequency Converter Mitsubishi FR-A741 ( $\mathrm{P}=22 \mathrm{~kW})$ with a motor ADCHR160M4U3 $18.5 \mathrm{~kW}$ powered by a frequency Converter Mitsubishi FR-A741 $\mathrm{P}=37 \mathrm{~kW}$, and with a motor ADCHR180M4 $\mathrm{P}=30 \quad \mathrm{~kW}$ when combining DC link circuits. ADCHR160M4U3 will operate in generator mode, and
ADCHR180M4U3 in motoring mode. The simulation results shown in figure 5 confirm the possibility of recovery during acceleration and deceleration of the line (current 12 changes its direction).

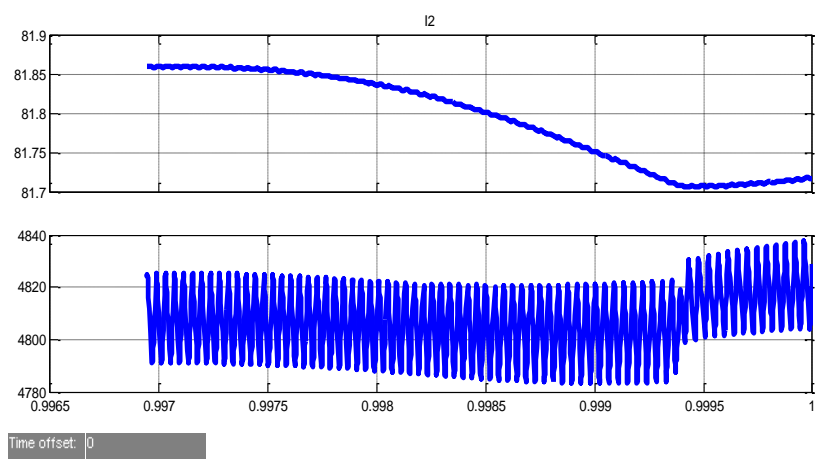

Fig. 5. Characteristics of the system output ( upper graph current, lower-voltage).

\section{Conclusion}

The graphs obtained from the simulation (Fig. 4) showed that the current I1 in the network increases when the load current of the secondary power source increases in both the motor and generator modes of the electric drive. The current phase relative to the voltage determines the power consumption from the network or recovery. When energy is recovered to the network, the current phase relative to the voltage is equal to $180^{\circ}$, and when energy is consumed in the motor mode- $0{ }^{\circ}$ The research results confirm the possibility of using a common DC bus for frequency drives as part of a multi-motor electric drive of production lines in order to use recovery energy to reduce energy consumption. Economic calculations have shown that if this scheme is implemented, the energy consumed from the network is reduced by $5652.14 \mathrm{~W}$ and will be $26386.54 \mathrm{~W}$. The approximate energy savings will be $25,787,9 \mathrm{kWh}$ per year.

\section{References}

[1] R.N. Ganiev, S.N. Shatunov, Frequencycontrolled electric drive with recovery as part of the cordline production of truck tires, Bulletin of the Chuvash University, 3, 44-52 (2018)

[2] R. N. Ganiev, Reversible frequency converters in the composition of multimotor electric drives, IOP Conference Series: Materials Science and Engineering, International Scientific Electric Power Conference 23-24 May 2019, Saint Petersburg, Russian Federation, 643012068 (2019)

[3] J.E. Valdez-Resendiz, J.C. Mayo-Maldonado, A. Llamas-Terres, J.C. Rosas-Caro, Quadratic boost converter based on stackable switching stages IET Power Electronics 11, 8 (2018)

[4] A. Rehaoulia, H. Rehaoulia, F. Fnaiech, Output voltage quality analysis of three-phase multilevel inverters Electrical Motorering, Archiv für Elektrotechnik 100, 2, 733-739 (2018) 
[5] S. Zambou, R. Nuessl, F.M. Azeutsap, S.S. Zekeng, J.M. Ndjaka, B. Magunje, S.D. Walton, E.O Jonah, M. Harting, D.T. Britton, Switching alternating current (ac) using a fully screen-printed current-driven transistor, IET Power Electronics 11, 1, 168-174 (2018)

[6] P. Záskalický, Mathematical model of a fivephase voltage-source pwm-controlled inverter, Electrical Motorering, Archiv für Elektrotechnik 99, 4, 1179-1184 (2017)

[7] K. Bernacki, Z. Rymarski, Electromagnetic compatibility of impedance source inverters, Elektronika ir Elektrotechnika 23, 3, 55-63 (2017)

[8] N. Prabaharan, K. Palanisamy, Analysis of cascaded h-bridge multilevel inverter configuration with double level circuit, IET Power Electronics 10, 9, 1023-1033 (2017)

[9] A.M. Airabella, G.G. Oggier, L.E. Piris-Botalla, G.O. García, C.A. Falco, C. Ramos, A. Martins, A. Carvalho, Semi-conductors faults analysis in dual active bridge dc-dc converter, Active filtering of dfig stator and rotor current harmonics caused by distorted stator voltages, European Power Electronics and Drives Journal 21, 1, 4354 (2011) 